\title{
Meat consumption providing a surplus energy in modern diet contributes to obesity prevalence: an ecological analysis
}

Wenpeng You ${ }^{1 *}$ and Maciej Henneberg ${ }^{1,2}$

\begin{abstract}
Background: Excessive energy intake has been identified as a major contributor to the global obesity epidemic. However, it is not clear whether dietary patterns varying in their composition of food groups contribute. This study aims to determine whether differences in per capita availability of the major food groups could explain differences in global obesity prevalence.

Methods: Country-specific Body Mass Index (BMI) estimates (mean, prevalence of obesity and overweight) were obtained. BMI estimates were then matched to mean of three year-and country-specific availability of total kilocalories per capita per day, major food groups (meat, starch, fibers, fats and fruits). The per capita Gross Domestic Product (GDP) and prevalence of physical inactivity for each country were also obtained. SPSS was used for log-transformed data analysis.

Results: Spearman analyses of the different major food groups shows that meat availability is most highly correlated with prevalence of obesity $(r=0.666, p<0.001)$ and overweight $(r=0.800, p<0.001)$ and mean BMI $(r=0.656, p<0.001)$ and that these relationships remain when total caloric availability, prevalence of physical inactivity and GDP are controlled in partial correlation analysis. Stepwise multiple linear regression analysis indicates that meat availability is the most significant predictors of prevalence of obesity and overweight and mean BMI among the food groups. Scatter plot diagrams show meat and GDP adjusted meat are strongly correlated to obesity prevalence.

Conclusion: High meat availability is correlated to increased prevalence of obesity. Effective strategies to reduce meat consumption may have differential effects in countries at different stages of the nutrition transition.
\end{abstract}

Keywords: Obesity, Food group, Meat, Macronutrient, Meat protein, Carbohydrates, Adaptation

\section{Background}

The global prevalence of obesity and its associated metabolic syndrome has increased markedly in adults and children over the past 20 years [1-6]. Once considered a problem only in high income countries, obesity is now dramatically on the rise in low- and middle-income countries, particularly in urban settings. Obesity has been consider as one of major risk factors for a number of chronic diseases, including diabetes, cardiovascular diseases and cancer [7]. The World Health Organization

\footnotetext{
* Correspondence: wenpeng.you@adelaide.edu.au

${ }^{1}$ Biological Anthropology and Comparative Anatomy Unit, School of Medical

Sciences, the University of Adelaide, Adelaide, SA 5000, Australia

Full list of author information is available at the end of the article
}

(WHO) describes obesity as one of the most blatantly visible, yet most neglected, public health problems [8].

Body weight status is determined with reference to the body mass index (BMI). Those with a BMI ranging between $18-24.99 \mathrm{~kg} / \mathrm{m}^{2}$ are considered healthy. In WHO statistics, population segment consisting of individuals with a BMI equal to $25 \mathrm{~kg} / \mathrm{m}^{2}$ or higher is classified as overweight whilst obesity is reserved for those reaching or exceeding a BMI of $30 \mathrm{~kg} / \mathrm{m}^{2}$ [9]. WHO also publishes the country-level estimate of mean BMI in $\mathrm{kg} / \mathrm{m}^{2}$ to reflect its general body weight status.

It is well recognised that diet and lifestyle are the major contributing factors, yet previous population based dietary interventions that focus on one dietary 
factor such as reducing fat intake have been ineffective in combating the increasing rates of obesity [10-12]. Although energy intake is recognised as a major contributing factor to the growing obesity rates, there is increasing evidence that some dietary patterns have a greater influence on promoting body weight gain than others [13]. Food production modernization and rising income levels in last decades have made a range of foods easily available and affordable with less seasonal variation [14]. To combat obesity a common approach has been to limit energy intake, although weight loss is often achieved in the short term, studies are unable to show that this weight loss is maintained in the long term [15]. Of the food groups, meat when consumed at high levels has been shown to increase weight gain due to its high energy density and/or fat content [16-20]. Whether and how nutrients provided by other food groups contribute to this effect is not known. In addition, there is little evidence that diet containing different composition of food groups or macronutrients may also be important in determining the development of obesity, yet this has yet to be evaluated at the population level.

Our group recently suggested that the portion size of animal and plant products in the modern diet has contributed to obesity prevalence [21]. People from different countries have different availability of meat due to their affordability and dietary habits. We hypothesise that the persistent consumption of high quantities of meat contributes to increasing adiposity and thus obesity when carbohydrates and fats consumed are sufficient or overabundant to satisfy caloric needs. Here we test this hypothesis using three country specific variables defined by BMI values (prevalence of obesity and overweight and mean BMI) and per capita availability data of various major groups of foodstuffs (meat, starch crop, fruits, fats and fibers) and the three macronutrients (fats, proteins and carbohydrates).

\section{Methods}

The country specific data were collected for this ecological study:

\section{The WHO Global Health Observatory (GHO) data}

The WHO Global Health Observatory (GHO) data on estimated prevalence rates of obesity and overweight (percent of population aged $18+$ with $\mathrm{BMI} \geq 30$ and $25 \mathrm{~kg} / \mathrm{m}^{2}$ respectively) and on mean $\mathrm{BMI}$ of the population aged 18 + by country was obtained for the year 2010 [22]. We did not use the most recent version of three levels of BMI $(\mathrm{BMI}=30, \mathrm{BMI}=25$ and mean $\mathrm{BMI})$ in 2014, but used the 2010 year data because of other key variables of interest (described below). We included overweight prevalence and mean BMI in our study in case meat availability was a late-stage predictor of obesity.
We also captured the estimated prevalence rate of physical inactivity for each country for the population aged 18+ [22]. The estimated prevalence rate of physical inactivity is defined as percent of defined population attaining less than 150 minutes of moderate-intensity physical activity per week, or less than 75 minutes of vigorous-intensity physical activity per week, or equivalent.

The GHO is an initiative of the WHO to share data on global health, including statistics by country and information about specific diseases and health measures. The GHO specifically assembles prevalence data of the biological risk factors, including obesity, overweight and mean BMI for WHO Member States using standardized protocols (http://www.who.int/gho/ncd/methods/en/).

\section{The FAOSTAT Food Balance Sheet (FBS) data}

The FAOSTAT Food Balance Sheet (FBS) data on major food group availability per capita per day of: i) total meat; ii) starch crops (mixed cereals and starchy root); iii) fibers (vegetables and pulses); iv) fats (plant oils and animal fats) and v) fruits [23]. The food items in each food group are indicated in the Supporting Information (Additional file 1: Table S1).

We also extracted the availability of grand total calories and macro-nutrients of fats (animal and plant, in g/capita/ day) and proteins (animal, plant and meat, in g/capita/day) from FBS for our study. As animal protein includes meat protein, we subtracted meat protein from the animal protein to obtain the variable, "Animal protein, excluding meat protein" for more precise data analysis. Following the Atwater system [24], we calculated the energy from carbohydrates using the formula: carbohydrates energy per day = total calories- fat (grand total, in gram/day) $\times 9-$ protein (total, in gram/day) $\times 4$. For carbohydrates availability in g/ capita/day, we used the energy in kilocalories (kcal) divided by 4 . Because obesity develops after cumulative exposure to dietary risks (i.e. high intake of risk food groups today does not lead to immediate obesity, but a prolonged exposure to high intake of risk food type(s) is required.), we calculated the mean grams per person per day over a 3-year period (2007-2009) in each of these food categories to represent typical long-term exposure to each of these dietary components. The rationale for this decision is that studies have shown that three years is a practical period to develop metabolic syndrome leading to obesity after exposure to dietary risks (i.e. high intake of meat today does not lead to immediate obesity) [25-27]. Using the mean of three years of nutrients and food groups may also reduce the random errors during the data collection and calculation by FAO.

The FAOSTAT database disseminates statistical data collected and maintained by the FAO. FAOSTAT data are provided as a time-series from 1961 in most domains through the Food Balance Sheet (FBS, http://faostat3.fao.org/home/E). The FBS presents a comprehensive 
picture of the pattern of a country's food supply during a specified reference period. The FBS shows for each food item i.e. each primary commodity availability for human consumption which corresponds to the sources of supply and its utilisation. The total quantity of foodstuffs produced in a country added to the total quantity imported and adjusted to any change in stocks that may have occurred since the beginning of the reference period gives the supply available during that period. On the utilisation side a distinction is made between the quantities exported, fed to livestock + used for seed, losses during storage and transportation, and food supplies available for human consumption. The per capita supply of each such food item available for human consumption is then obtained by dividing the respective quantity by the related data on the population actually partaking in it [28].

Minimum Dietary Energy Requirements, expressed as $\mathrm{kcal}$ per person per day, is the weighted average of the minimum energy requirements of the different gender-age groups in the population with light activity. Grantham et al. reported that when a mixed meal of protein, carbohydrate and fat is consumed, carbohydrates and fats are digested faster and metabolised to satisfy body's energetic needs while slower digested protein is ultimately and stored as fat [29]. Therefore, we extracted the Minimum Dietary Energy Requirements from the FAO website (http://www.fao.org/) and compared it and with the energy from carbohydrates and fats by country to see if the energy from the proteins is the surplus.

\section{The World Bank data}

The World Bank dataset measures progress on aggregate outcomes for member countries for selected indicators. GDP PPP is gross domestic product converted to international dollars using purchasing power parity rates (http:// data.worldbank.org/indicator/NY.GDP.PCAP.PP.CD) [30] . GDP PPP is the measure of average income in constant 2010 \$US adjusted for purchasing power parity for crosscountry comparability.

WHO, FAO and the World Bank are intergovernmental organizations using specialized information relevant to their respective fields. Their professional personnel should have evaluated these data in consideration of their possible use, e.g. for scientific research and decision making, before they were published. Therefore, the data reporting is as free of bias and error as it can be with government statistics. This means that errors are reduced but some inaccuracies related to reporting quality may still be present in the data. Similar data from the same sources were recently used to analyse the relationships between nutrients and obesity [31, 32] and diabetes [33-35] in a number of publications.

We obtained data for 170 countries after we matched the prevalence estimates of obesity and overweight and mean BMI to the year-and country-specific food and other variables. Each country was treated individually as the subject and all their availability for other variables information was analysed. The detailed information of country-level estimates is in the Supporting Information (Additional file 2: Table S2).

For particular analyses, the number of countries included may have differed somewhat because all information on other variables was not uniformly available for all countries due to unavailability from relevant UN agencies. All the data were extracted and saved in Microsoft Excel ${ }^{\circ}$ for analysis. Data sources and summary statistics are further described in the Supporting Information (Additional file 3: Table S3).

\section{Statistical analysis}

The prevailing dogma of obesity is that obesity is an affluence related medical conditions [36], which is generally caused by eating too much (too much calories intake) [37] and moving too little (physically inactive) [38]. Therefore, in this study we used GDP PPP, total calories and prevalence of physical inactivity as the potential confounders and the other variables are divided into two sets, i.e. major food group and macronutrient for data analysis in 5 steps.

Spearman rank correlation analyses was used to evaluate the strength and direction of the associations between food group and macronutrient availability for consumption and prevalence estimates of overweight and obesity and mean BMI.

Partial correlation was used to find the unique variance between each food group and macronutrient and prevalence of obesity and overweight and mean BMI respectively while eliminating the variance from total calories, GDP PPP and physical inactivity. In order to show the independent correlation of meat and meat protein to the three variables defined by $\mathrm{BMI}$ (BMI $\geq 30, \mathrm{BMI} \geq 25$ and mean $\mathrm{BMI})$ respectively, we controlled for three potential confounders (total calories, GDP PPP and physical inactivity) plus all other food groups and all other macronutrient variables respectively for partial analysis.

Stepwise multiple linear regression modelling was performed to identify and rank predictors (independent variables) of prevalence of obesity, overweight and mean BMI respectively from two sets of data of food groups and macronutrients respectively.

Scatter plots were used to explore the relationship between meat and meat protein (both GDP adjusted) and three variables defined by BMI. Scatter plots were also used to explore the relationship between prevalence of obesity and each food group and macronutrient respectively.

Human diet patterns varying in different food components may be affected by the types of food availability in a particular region, socio-economic status and cultural 
beliefs. In order to demonstrate that correlation universally exists between meat availability and obesity regardless of these factors, countries were grouped for correlation analyses. The criteria for grouping countries the World Bank income classifications [39], WHO regions [40], countries sharing specific characteristics like geography, culture, development role or socio-economic status, like Latin America and the Caribbean (LAC) [41], Organisation for Economic Co-operation and Development (OECD) [42], Asia-Pacific Economic Cooperation (APEC) [42], Southern African Development Community (SADC) [43], the Arab World [42], Latin America (LA), and Asia Cooperation Dialogue (ACD) [44]. All the country listings are sourced from their official websites for matching except LA which is self-classified based on region primarily speaking romance languages. Countries included in LA are listed in the Supporting Information (Additional file 4: Table S4).

SPSS v. 22 (SPSS Inc., Chicago Il USA) was used for data analysis and the statistical significance was set at the
0.01 level (two-tailed). Prior to analysis data were logtransformed to bring their distributions close to normal.

\section{Results}

Spearman rank correlation analyses of the different major food groups shows that meat availability is most highly correlated with prevalence of obesity $(r=0.666, p<0.001)$ and overweight $(r=0.800, p<0.001)$ and mean BMI $(r=$ $0.656, p<0.001)$ and that these relationships remain when total caloric availability, prevalence of physical inactivity and GDP PPP are kept statistically constant in partial correlation analysis (Table 1). Starch crop availability is strongly in negative correlation with prevalence of obesity $(r=-0.205, p<0.01)$ and overweight $(r=-0.228, p<0.01)$ and mean BMI $(r=-0.318, p<0.001)$, but the relationship does not remain in our partial correlation analysis (Table 1). Interestingly, in Spearman rank correlation analyses fats group is second to meat in significant correlation with prevalence of obesity $(r=0.517, p<0.001)$ and

Table 1 Spearman and partial correlation between food groups and three variables defined by BMI (obesity, overweight and mean BMI)

\begin{tabular}{|c|c|c|c|c|c|c|}
\hline \multirow[t]{2}{*}{ Variables } & \multicolumn{3}{|l|}{ Spearman } & \multicolumn{3}{|l|}{ Partial } \\
\hline & $\mathrm{BMI} \geq 30$ & $\mathrm{BMI} \geq 25$ & BMI mean & $\mathrm{BMI} \geq 30$ & $\mathrm{BMI} \geq 25$ & BMI mean \\
\hline \multicolumn{7}{|l|}{ Food group } \\
\hline Meat, total & $0.666^{* * *}$ & $0.800^{* * *}$ & $0.656^{* * *}$ & $0.356^{* * *}$ & $0.421^{* * *}$ & $0.380^{* * *}$ \\
\hline Meat, total, all variable controlled ${ }^{a}$ & - & - & - & $0.357^{* * *}$ & $0.415^{* * *}$ & $0.339^{* * *}$ \\
\hline Fats (plant oil + animal fat) & $0.517^{* * *}$ & $0.728^{* * *}$ & $0.483^{* * *}$ & 0.077 & 0.166 & -0.005 \\
\hline Fruits, total & $0.467^{* * *}$ & $0.521^{* * *}$ & $0.461^{* * *}$ & 0.173 & $0.197^{*}$ & $0.258^{* *}$ \\
\hline Fibers (vegetables + pulses) & $0.315^{* * *}$ & $0.516^{* * *}$ & $0.330^{* * *}$ & $-0.197^{*}$ & -0.035 & -0.107 \\
\hline Starch (cereals + starchy root) & $-0.205^{* *}$ & $-0.228^{* *}$ & $-.318^{* * *}$ & 0.078 & -0.011 & -0.085 \\
\hline \multicolumn{7}{|l|}{ Macronutrient } \\
\hline Meat protein & $0.673^{* * *}$ & $0.793^{* * *}$ & $0.660^{* * *}$ & $0.392^{* * *}$ & $0.431^{* * *}$ & $0.400^{* * *}$ \\
\hline Meat protein, all variable controlled ${ }^{b}$ & - & - & - & $0.316^{* * *}$ & $0.183^{*}$ & $0.299^{* * *}$ \\
\hline Animal protein, excluding meat protein & $0.522^{* * *}$ & $0.741^{* * *}$ & $0.516^{* * *}$ & 0.017 & $0.214^{*}$ & 0.029 \\
\hline Plant protein, total & -0.094 & -0.063 & -0.094 & $-0.227^{*}$ & $-0.333^{* * *}$ & $-0.248^{*}$ \\
\hline Animal fats, total & $0.581^{* * *}$ & $0.803^{* * *}$ & $0.574^{* * *}$ & $0.196^{*}$ & $0.379^{* * *}$ & $0.222^{*}$ \\
\hline Plant fats, total & $0.440^{* * *}$ & $0.570^{* * *}$ & $0.371^{* * *}$ & $0.252^{*}$ & $0.230^{* *}$ & $0.201^{*}$ \\
\hline Carbohydrates & $0.230^{* *}$ & $0.202^{* *}$ & $0.208^{* *}$ & $-0.193^{*}$ & $-0.324^{* * *}$ & -0.166 \\
\hline \multicolumn{7}{|l|}{ Potential confounder } \\
\hline Calories, total & $0.623^{* * *}$ & $0.805^{* * *}$ & $0.563^{* * *}$ & - & - & - \\
\hline GDP PPP & $0.642^{* * *}$ & $0.808^{* * *}$ & $0.610^{* * *}$ & - & - & - \\
\hline Physical Inactivity & $0.438^{* * *}$ & $0.384^{* * *}$ & $0.460^{* * *}$ & - & - & - \\
\hline
\end{tabular}

Spearman's rho of correlation and partial correlation are reported. Numbers of countries (df) included in the two correlation analysis are 161-170 and 115-123 respectively. ${ }^{*} P<0.05,{ }^{* *} P<0.01 ;{ }^{* *} P<0.001$

$\mathrm{BMI} \geq 30$ and $\mathrm{BMI} \geq 25$ are percentages of defined population with a body mass index (BMI) of no less than $30 \mathrm{~kg} / \mathrm{m} 2$ and $25 \mathrm{~kg} / \mathrm{m}^{2}$ respectively. BMI mean is the mean body mass index (BMI) in $\mathrm{kg} / \mathrm{m}^{2}$ of defined population

Availabilities of food types (meat, fats, fruits, fibers and starch) and macronutrients (meat protein, animal protein (excl. meat protein), plant protein, animal fats, plant fats and carbohydrates) are expressed in $\mathrm{g} /$ capita/day

Total calories is in kcal/capita/day. GDP PPP is in per capita USD per year. Physical inactivity is defined as the percent of defined population attaining less than 150 minutes of moderate-intensity physical activity per week, or less than 75 minutes of vigorous-intensity physical activity per week, or equivalent

${ }^{\text {a }}$ Partial analysis with controlling for fats (plant oil + animal fat), Fruits, total (total), Fibers (vegetables + pulses) and Starch (cereals + starchy root) and the three potential confounders, calories, GDP PPP and physical activity

${ }^{b}$ Partial analysis with controlling for Animal protein (excluding meat protein), Plant protein (total), Animal fats (total), Plant fats (total) and Carbohydrate energy and the three potential confounders, calories, GDP PPP and physical activity 
overweight $(r=0.728, p<0.001)$ and mean BMI $(r=0.438$, $p<0.001)$. However, these relationships nearly disappear in the succeeding partial correlation analysis with controlling for total caloric availability, prevalence of physical inactivity and GDP (Table 1).

Table 1 also presents the strongest significant correlation between meat protein availability and prevalence of obesity $(r=0.673, p<0.001)$ and overweight $(r=0.793, p<0.001)$ and mean BMI $(r=0.660, p<0.001)$. This correlation is sustained when total caloric availability, prevalence of physical inactivity and GDP PPP are kept statistically constant in partial correlation analysis (Table 1). Animal protein (excluding meat protein) shows quite high nonparametric correlation coefficients with prevalence of obesity $(r=$ $0.522, p<0.001)$ and overweight $(r=0.741, p<0.001)$ and mean BMI $(r=0.516, p<0.001)$, but this correlation is not sustained in succeeding partial analysis (Table 1). Plant protein group shows slightly negative correlation with all the three stages of body weight (BMI $\geq 30, \mathrm{BMI} \geq 25$ and mean BMI) in Spearman rank correlation analyse, but the relationships are relative strong (not at significance level of $p<$ 0.001 yet) in partial correlation analysis with controlling for total caloric availability, prevalence of physical inactivity and GDP (Table 1). Both animal fat and plant oil food types are correlated with prevalence of obesity $(r=0.581, p<$ 0.001 and $r=0.440, p<0.001$ respectively) and overweight ( $r=0.803, p<0.001$ and $r=0.570, p<0.001$ respectively) and mean BMI $(r=0.574, p<0.001$ and $r=0.371, p<0.001$ respectively) in Spearman rank correlation analyses. However, in the succeeding partial correlation analysis the significance either does not remain or becomes weak except the correlation between animal fats group and prevalence overweight $(r=0.358, p<0.001)$. Carbohydrates energy shows the relative significant correlation with prevalence of obesity $(r=0.230, p<0.01)$ and overweight $(r=0.202, p<$ $0.01)$ and mean BMI $(r=0.208, p<0.01)$, but this relationship becomes slightly negative in partial correlation analysis (Table 1).

Meat and meat protein are in significant correlation with prevalence of obesity $(r=0.356, p<0.001$ and $r=$ $0.392, p<0.001$ respectively) and overweight $(r=0.421$, $p<0.001$ and $r=0.431, p<0.001$ respectively) and mean BMI $(r=0.380, p<0.001$ and $r=0.400, p<0.001$ respectively) when we control for the potential confounders, total calories, GDP and physical inactivity in partial analysis (Table 1). Meat availability is also significantly correlated to prevalence of obesity $(r=0.357, p<0.001)$ and overweight $(r=0.415, p<0.001)$ and mean BMI $(r=$ 0.339, $p<0.001)$ when we controlled for the four other food groups and the three potential confounders in partial correlation. We have the similar correlation of meat protein to three variables defined by BMI respectively when we controlled for the other five macronutrients and the three potential confounders (Table 1).

Table 2 presents that meat and meat protein availability are the most significant predictors of prevalence of obesity ( $\mathrm{R} 2=0.468$ and $\mathrm{R} 2=0.472$ respectively) and overweight ( $R 2=0.628$ and $R 2=0.614$ respectively) and mean BMI $(\mathrm{R} 2=0.507$ and $\mathrm{R} 2=0.498$ respectively) when all food groups and macronutrients were entered into the regression model respectively for stepwise multiple linear regression analysis.

The relationship between GDP adjusted meat availability and prevalence of obesity and overweight and mean BMI is noted to be logarithmic with strong correlations (Fig. 1). Meanwhile relationship between GDP adjusted

Table 2 Results of stepwise multiple linear regression analyses to identify food group and macronutrient predictors of three variables defined by BMI

\begin{tabular}{|c|c|c|c|c|c|c|}
\hline \multirow[b]{2}{*}{ Rank } & \multicolumn{2}{|l|}{$\mathrm{BMI} \geq 30$} & \multicolumn{2}{|l|}{$\mathrm{BMI} \geq 25$} & \multicolumn{2}{|l|}{ BMI, Mean } \\
\hline & Variables entered & Adjusted $R^{2}$ & Variables entered & Adjusted $R^{2}$ & Variables entered & Adjusted $R^{2}$ \\
\hline \multicolumn{7}{|c|}{ Food groups } \\
\hline 1 & Meat, total & 0.468 & Meat, total & 0.628 & Meat, total & 0.507 \\
\hline 2 & Fruits & 0.483 & Fibers (vegetables + Pulses) & 0.667 & Fruits & 0.538 \\
\hline 3 & Fats (animal fat + plant oil) & 0.494 & Fats (animal fat + plant oil) & 0.687 & - & - \\
\hline 4 & - & - & Fruits & 0.701 & - & - \\
\hline \multicolumn{7}{|c|}{ Macronutrients } \\
\hline 1 & Meat protein & 0.472 & Meat protein & 0.614 & Meat protein & 0.498 \\
\hline 2 & Plant oil & 0.522 & Animal protein, excl. meat protein & 0.666 & Plant oil & 0.526 \\
\hline 3 & Carbohydrates & 0.549 & Plant oil & 0.694 & Carbohydrates & 0.548 \\
\hline 4 & - & - & Carbohydrates & 0.714 & - & - \\
\hline
\end{tabular}

Stepwise multiple linear regression modelling is reported. Number of countries included in the analysis range from 157 to 166 $\mathrm{BMI} \geq 30$ and $\mathrm{BMI} \geq 25$ are percentages of defined population with a body mass index (BMI) of no less than $30 \mathrm{~kg} / \mathrm{m} 2 \mathrm{and} 25 \mathrm{~kg} / \mathrm{m} 2 \mathrm{respectively}$. BMI mean is the mean body mass index (BMI) in $\mathrm{kg} / \mathrm{m} 2$ of defined population

Availabilities of food types (meat, fats, fruits, fibers and starch) and macronutrients (meat protein, animal protein (excl. meat protein), plant protein, animal fats, plant fats and carbohydrates) are expressed in $\mathrm{g} /$ capita/day 


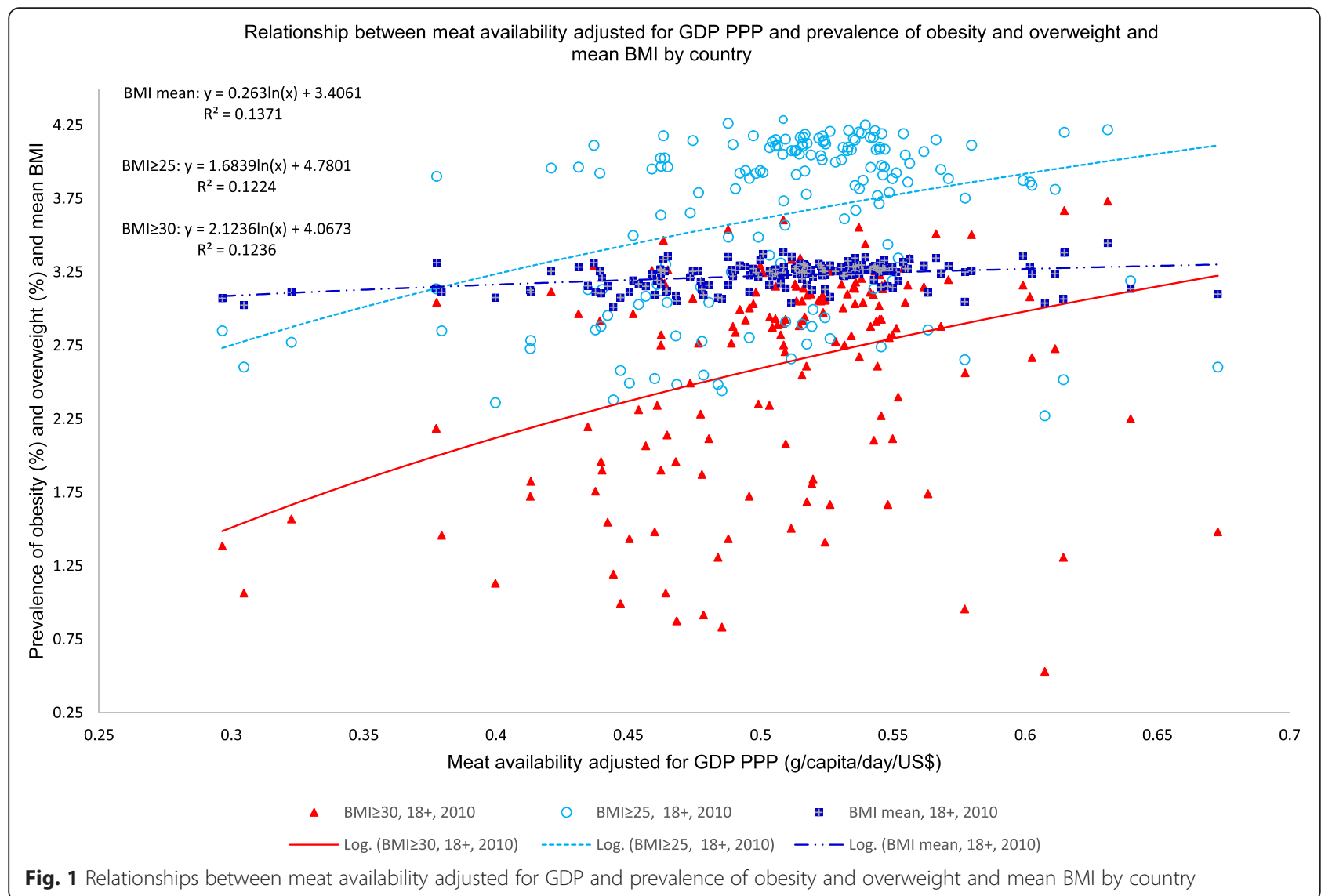

meat protein and the three levels of BMIs shows polynomial relationship with the three variables describing weight status (Fig. 2).

We also used scatter plots to show the relationship between prevalence of obesity and each food group and macronutrient. See the Supporting Information (Additional file 5: Figures S1 and Additional file 6: S2).

Table 3 shows that generally meat availability is positively correlated with prevalence of obesity and overweight and mean BMI can be observed in different country groupings regardless of cultural backgrounds, economic levels and geographic locations of the clustered countries.

Based on the WHO region classifications, the positive correlation is observed in every region except in SEARO.

The correlation between meat availability and three variables defined by BMI can also be observed in the country groupings of the Arab World (geographically scattered in Asia and Africa) and LAC (located in Americas only) featured with the similar cultures respectively. The trends also present in two functional alliances, OECD and APEC although the former comprises developed countries only and the latter is comprised of both developing and developed countries.

We subtracted grand total protein energy from grand total calories to allow us to obtain the energy from grand total fats and carbohydrates in $\mathrm{kcal} /$ capita/day [28], which is more than the minimum dietary energy requirements in all countries except Haiti $(-29.3 \mathrm{kcal} /$ capita/day) and Zambia (-90.9 kcal/capita/day).

\section{Discussion}

The worldwide secular trend of increased obesity prevalence likely has multiple aetiologies, which may act through multiple mechanisms. By examining the per capita availability of the major food groups and macronutrients for 170 countries we have shown that populations with the highest availability levels of meat (meat protein) have the highest prevalence of overweight and obesity and greatest mean BMI. Meat is most significant predictor of prevalence of obesity and overweight and mean BMI at country level, and this relationship is independent of total calories availability, GDP and prevalence of physical inactivity. Our finding of the relationship between meat availability and body weight increase is consistent with data from Belgium [45] and USA [46-48] that showed a positive association between obesity prevalence among adults and children and meat consumption. Studies in China also showed that high intakes of meat products, including red meat were associated with the prevalence of obesity $[49,50]$. A survey in Ireland showed that young girls avoided meat because they 


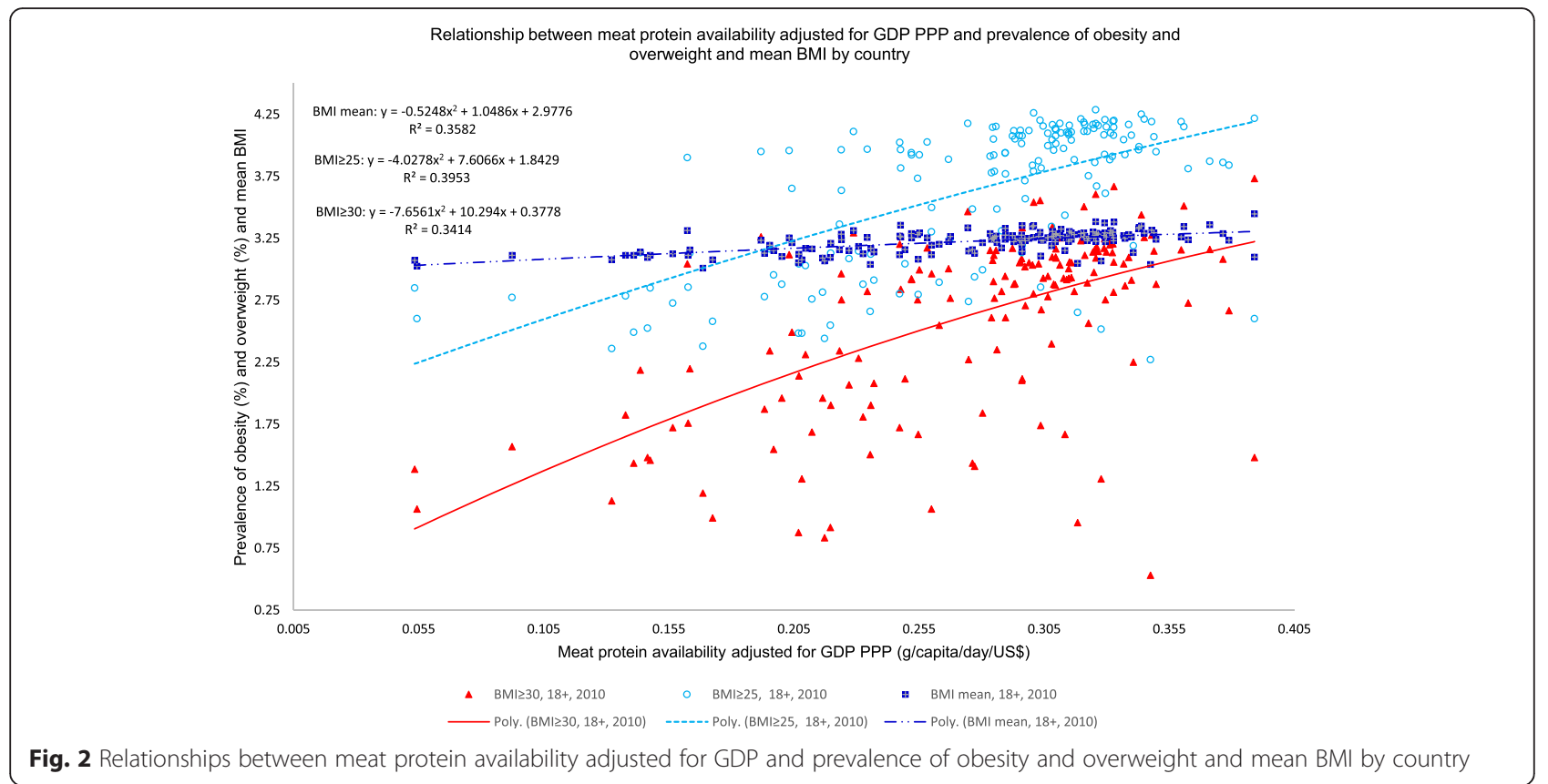

concluded that "meat is a fattening food" [51]. The association for the Chinese population is particularly striking as the changes in dietary patterns and obesity rates have occurred very rapidly [52]. All these studies based on the individual level held the view that fat in meat contributed to obesity or body weight increase even though fresh meat has been leaner than ever over the past few decades due to leaner animals being bred and improved butchery and feeding techniques that make fat content fall significantly $[53,54]$. The correlation we found in this study between the three major macronutrients or their proxy food groups and three variables defined by BMI is compatible with Grantham et al.'s finding that, in modern diet, carbohydrates and fats are digested to satisfy body's energetic needs while protein is converted and stored as fat [29].

The human metabolic system has been adapting to forager diet for millions of years [55], and adaptations to an agriculture-based diet only started a few thousand years ago in most populations $[29,56]$. An evolutionary mismatch between modern dietary constituents and the food available prior to the agricultural revolution has long been considered a factor in the obesity epidemic [57]. In the Palaeolithic age our ancestors' diet comprised of what could be extracted from natural environments through gathering, scavenging and hunting and thus predominately consisted of animal protein [58]. In addition to hunting large animals, the main food sources included smaller animals such as amphibians, reptiles, invertebrates and their eggs, but also plant products, such as tubers, fruits and nuts that could be collected seasonally. In general, there was limited availability of animal and plant food, but plant sources were often least available [21]. Fats do not occur in large quantities in plants or wild animals. In the foraging situation ingested protein was mainly used for energy production as available carbohydrates from plants would be too scarce to satisfy human energy needs [55]. This use of protein was possible as humans have efficient deaminases that can convert amino acids to carbon skeletons that, when broken down to pyruvate can be processed in the citric acid cycle, or de novo lipogenesis, or gluconeogenesis [21]. Occasionally, when there was an abundant meat source, e.g. a large mammal, surplus ingested protein was efficiently stored in the human body as adipose tissue [59]. Thus the human metabolic system has evolved over thousands of years to predominately rely on animal protein and to a lesser degree carbohydrate and fats to satisfy our energy needs and to store surplus food intake into the adipose tissue [21]. Further support of human adaptation and dependence on protein for energy, comes from similarities in total energy intake (standardised by body mass) and intestinal tract morphology between modern humans and extant carnivores [21].

In the current study animal products provided less than half (3.1-44.5\%) of the individual daily energy requirement for all countries examined [23], and a majority of energy came from plant products. Interestingly, there are a number of different weight loss diets that are high in animal and low in plant products such as the Atkins Nutritional Approach [60-62]. Although these diets can be effective in reducing weight in the short term, energy restriction is difficult to maintain long term and a majority of people regain any weight that was lost [15]. Daily energy requirements of modern humans may be quickly and 
Table 3 Correlation of meat availability to three variables defined by BMl in different country groupings

\begin{tabular}{|c|c|c|c|}
\hline Country groupings & $\mathrm{BMI} \geq 30$ & $\mathrm{BMI} \geq 25$ & BMI, Mean \\
\hline Worldwide $(n=167)$ & $0.666^{* * *}$ & $0.800^{* * *}$ & $0.656^{* * *}$ \\
\hline \multicolumn{4}{|c|}{ World Bank income classifications } \\
\hline Low $(n=31)$ & 0.167 & 0.254 & 0.196 \\
\hline Low middle $(n=41)$ & $0.439^{* *}$ & $0.537^{* * *}$ & $0.465^{* *}$ \\
\hline Upper middle $(n=47)$ & 0.167 & 0.149 & 0.209 \\
\hline High $(n=48)$ & 0.241 & $0.631^{* * *}$ & $0.288^{*}$ \\
\hline \multicolumn{4}{|l|}{ WHO regions } \\
\hline $\operatorname{AFRO}(n=40)$ & $0.585^{* * *}$ & $0.612^{* * *}$ & $0.552^{* * *}$ \\
\hline $\operatorname{AMRO}(n=35)$ & $0.671^{* * *}$ & $0.606^{* * *}$ & $0.546^{* * *}$ \\
\hline $\operatorname{EMRO}(n=15)$ & $0.857^{* * *}$ & $0.879^{* * *}$ & $0.634^{*}$ \\
\hline EURO $(n=50)$ & $0.429^{* *}$ & $0.751^{* * *}$ & 0.128 \\
\hline $\operatorname{SEARO}(n=10)$ & -0.267 & -0.097 & 0.322 \\
\hline WPRO $(n=17)$ & 0.309 & 0.478 & 0.447 \\
\hline \multicolumn{4}{|c|}{ Countries grouped based on various factors } \\
\hline $\operatorname{APEC}(n=17)$ & $0.773^{* * *}$ & $0.858^{* * *}$ & $0.789^{* * *}$ \\
\hline Arab World $(n=13)$ & $0.687^{* *}$ & $0.687^{* *}$ & 0.426 \\
\hline $\operatorname{LAC}(n=26)$ & $0.609^{* * *}$ & $0.519^{* *}$ & $0.487^{* *}$ \\
\hline $\operatorname{OECD}(n=34)$ & 0.243 & $0.607^{* * *}$ & 0.285 \\
\hline $\operatorname{SADC}(n=14)$ & $0.890^{* * *}$ & $0.952^{* * *}$ & $0.802^{* * *}$ \\
\hline $\operatorname{ACD}(n=26)$ & $0.593^{* * *}$ & $0.720^{* * *}$ & $0.707^{* * *}$ \\
\hline $\operatorname{LA}(n=20)$ & $0.557^{*}$ & $0.675^{* * *}$ & 0.433 \\
\hline
\end{tabular}

Spearman's rho of correlation is reported. Number of countries included in the analysis range from 161 to $170 .{ }^{*} P<0.05,{ }^{* *} P<0.01 ;{ }^{* *} P<0.001$

$\mathrm{BMI} \geq 30$ and $\mathrm{BMI} \geq 25$ are percentages of defined population with a body mass index (BMI) of no less than $30 \mathrm{~kg} / \mathrm{m} 2$ and $25 \mathrm{~kg} / \mathrm{m} 2$ respectively. BMI mean is the mean body mass index (BMI) in $\mathrm{kg} / \mathrm{m} 2$ of defined population Availabilities of food types (meat, fats, fruits, fibers and starch) and macronutrients (meat protein, animal protein (excl. meat protein), plant protein, animal fats, plant fats and carbohydrates) are expressed in $\mathrm{g} / \mathrm{capita}$ /day

easily satisfied by digesting plant products rich in carbohydrates $[21,29,50]$ whereas consumed concurrently animal products, including meat that are more costly and slower to digest, will be metabolised into fat and stored [21]. The FAO/WHO currently recommends that our dietary protein should make up 10-15 percent of calorie intake [63]. It has been reported that consuming an amount of protein above the $\mathrm{FAO} / \mathrm{WHO}$ recommendation may be deleterious for weight maintenance through adult life [64]. In support of this, the PANACEA project which used data from the EPIC cohort [65] showed that participants consuming more than $22 \%$ of energy from protein had 23$24 \%$ higher risk of becoming overweight or obese than participants consuming a diet low in protein $(\leq 14 \%)$ [65]. Additionally, a $5 \%$ higher proportion of protein at the expense of carbohydrates was associated with a $247 \mathrm{~g}$ weight gain in men $(95 \% \mathrm{CI}=(160,334))$ and a $388 \mathrm{~g}$ weight gain $(296,480)$ in women after 5 years [65]. Furthermore, increasing the proportion of fat by $5 \%$ at the expense of carbohydrates during the same period showed no association with body weight increase [65].

Experiments among young males and rats undertaken by Mikkelsen et al. [66] and Toden et al. [67] respectively did not show the high meat protein quantity was associated with body weight increase. The underlying reasons may be that the used diets contained too much meat protein which was over $\mathrm{FAO} / \mathrm{WHO}$ recommended level and/or that these experiments focused on one or two sources of proteins, which did not reflect the actual protein metabolism within human body. Two case controlled studies have shown that adults and children consuming vegetarian diets have lower BMI values and a lower prevalence of obesity $[68,69]$. A medical and performance testing of 46,684 Swiss showed that obesity rates were also markedly lower in vegetarian adults [29] and epidemiological studies have consistently shown that vegetarians are thinner than comparable non-vegetarians [70]. A meta-analysis of adult vegetarian diet studies estimated a reduced weight difference of $7.6 \mathrm{~kg}$ for men and $3.3 \mathrm{~kg}$ for women, which resulted in a 2-point lower BMI [68]. Although there are some animal data suggesting that diets low in protein may increase the prevalence of obesity [71], evolutionary differences between humans and other animal species may explain our different metabolic response to dietary protein [72]. Rats [73] and mice [74] model experiments have shown that dairy protein rich diet reduces adiposity, which might be interpreted that the associations between dairy protein and overweight and obesity are not as strong as meat protein in this study. Our results show animal protein (excluding meat protein) is associated with the three stages of BMIs, but not as significantly as meat protein does may be because protein from dairy [73] and fish products [75] don't contribute to body weight increase.

There is a growing body of evidence which suggests that increased plant protein intakes are protective of body weight gain. A longitudinal association study in the US showed that people with the highest levels of plant protein intake had a reduced risk of being obese [48]. A similar association was found in the Belgian population using a food consumption survey [45]. These findings are consistent with the current study which showed that plant protein consumption rates were inversely associated with prevalence of both overweight and obesity [50] and mean BMI. Plant and meat protein may have different effects on body weight [48] because of their differences in amino acid composition [76]. Generally, dietary plant protein in food is mixed with indigestible carbohydrate (fiber) that can reduce plant protein digestibility. Therefore, plant protein varies in its digestibility and may provide considerably less energy compared to meat proteins.

The current study shows an inverse association between starch food group (mixed cereals and starchy 
root) and carbohydrates availability and prevalence of overweight and obesity and mean BMI. Cereals and starchy roots are grown in greater quantities and provide more food energy worldwide than any other type of crop. Carbohydrates are not an essential nutrient in humans $[77,78]$ even though they are a common source of energy. For instance, carbohydrate content in foods provide 70 percent or more of the energy intake of the population in the developing countries and about 40 percent in the United States and Europe [79]. Humans are the only large mammal that derives a majority of its energy by absorbing and metabolising carbohydrate. Because carbohydrate metabolism primarily concentrates on the oxidation of carbohydrates in the direct production of energy, this rarely produces fat $[77,80]$.

Our results show that both plant oils and animal fats are significantly associated with mean BMI, overweight and obesity in Spearman analysis, but the significance of this relationship disappears or is reduced because we controlled for total calories, GDP and prevalence of physical inactivity in partial correlation analysis. Numerous studies have shown increased intakes of dietary fat increase obesity risk/development [81-85]. However, a causal relationship between fat intake and obesity prevalence based on these studies [86-88] is difficult to demonstrate. Furthermore, the third American National Health and Nutrition Examination Survey showed that in the past two decades in United States, the prevalence of obesity has increased whereas the fat consumption was reduced $[89,90]$. Therefore, the increase in obesity cannot be explained by changes in dietary fat alone.

A strength of this study is that we used per capita availability data from 170 countries which enabled us to examine relationships in food group and macronutrient intake and how they may explain differences in the rates of prevalence of obesity and overweight and mean BMI at population level. However, there are several limitations in this study. Firstly, although we attempted to remove confounding effects of variables such as GDP, caloric etc. by means of partial correlation analysis, some confounding factors may still influence correlation we found. Secondly, there may be some variables not included in our analysis that influence the correlation found in this study. It is however difficult to see what such variables may be. Thirdly, we could only use an international food database that tracks the general market availability of different food types, not the actual human consumption. There are no direct measures of actual human consumption that can account for food wastage and provide precise measures of food consumption internationally. Fourthly, we were unable to analyze associations of food groups with obesity by each individual food item at country level. One of the main reasons is that some country may not access some particular food item due to its availability in their region, socio-economic status or cultural beliefs. For instance, pig meat (pork) is not consumed in Muslim countries or less consumed in countries with Muslim population, but they consumed mutton and lamp and other animal meat which share similar nutritional properties. Finally, the data analysed are calculated per capita in each country, so we can only demonstrate a relationship between food group availability and obesity, overweigh and mean BMI at a country level, which does not necessarily correspond to the same relationships holding true at the individual level. Prospective cohort studies are proposed to explore these associations further.

\section{Conclusion}

By examining the per capita availability of macronutrients and the major food groups for 170 countries we are able to identify that countries with dietary patterns that are higher in meat have greater rates of obesity and overweight and higher mean BMI. Considering the findings of adverse effect of obesity on the risk of other chronic diseases revealed by other studies as well as the environmental impact of meat production, the country authorities may advise people not to adopt a high-meat diet for long-term healthy weight management.

\section{Ethics}

All the data supporting our findings in this paper were freely downloaded from the United Nations (UN) agencies' websites. No ethical approval or written informed consent for participation was required.

\section{Consent to publish}

Not applicable.

\section{Availability of data and materials}

All data for this study are publicly available and are ready for the public to download at no cost from the official websites of the World Bank, the WHO and FAO. Use of these data for this research falls within these UN agency's public permission in their terms and conditions. There is no need to have the formal permission to use the data for this study. The sources and data robustness have been described in the section of "Methods". Furthermore, all the data supporting our findings are contained within the Supplemental File titled, Additional file 2: Table S2 Detailed information of country-level estimates.

\section{Additional files}

Additional file 1: Table S1. Food items in each food groupR4. (DOCX $14 \mathrm{~kb}$ )

Additional file 2: Table S2. Detailed information of country-level estimatesR4. (XLSX $37 \mathrm{~kb}$ ) 
Additional file 3: Table S3. Data descriptive and summaryR4. (XLSX $16 \mathrm{~kb}$ )

Additional file 4: Table S4. Countries included in LAR4. (PDF 8 kb) Additional file 5: Figure S1.

Additional file 5: Figure S1. Scatter plots to show the correlation between each food group and obesity prevalence. (PDF $1.17 \mathrm{mb}$ )

Additional file 6: Figure S2. Scatter plots to show the correlation between each macronutrient and obesity prevalenceR4. (PDF 537 kb)

\section{Abbreviations}

ACD: Asia Cooperation Dialogue; AFRO: WHO Regional Office for Africa; AMRO: WHO Regional Office for the Americas; APEC: Asia-Pacific Economic Cooperation; BMI: body mass index; Cl: confidence interval; EMRO: WHO Regional Office for the Eastern Mediterranean; EPIC: The European Prospective Investigation into Cancer and Nutrition; EURO: WHO Regional Office for Europe; FAO: The Food and Agriculture Organization of the United Nations; FBS: Food Balance Sheet; GDP: gross domestic product; GDP PPP: gross domestic product per capita based on purchasing power parity; GHO: Global Health Observatory; LA: Latin America; LAC: Latin America and the Caribbean; OECD: The Organisation for Economic Co-operation and Development; PANACEA: Physical Activity Nutrition, Alcohol, Cessation of Smoking, Eating Out of Home and Obesity; SADC: Southern African Development Community; SEARO: WHO Regional Office for South-East Asia; SPSS: Statistical Package for the Social Sciences; UN: The United Nations; USA: United States of America; WHO: World Health Organization; WPRO: WHO Regional Office for the Western Pacific.

\section{Competing interests}

The authors declare that they have no competing interests.

\section{Authors' contributions}

WPY reviewed the literature and obtained the data. MH and WPY formulated the hypothesis relating food groups to obesity, analysed the data and interpreted results and wrote the text. Both authors approved the final version of the manuscript.

\section{Acknowledgments}

The authors express appreciation to the Statistics Department of FAO for the assistance in locating and defining the data.

\section{Funding}

There was no funding for this project.

\section{Author details}

${ }^{1}$ Biological Anthropology and Comparative Anatomy Unit, School of Medical Sciences, the University of Adelaide, Adelaide, SA 5000, Australia. ${ }^{2}$ Institute of Evolutionary Medicine, University of Zurich, Zürich, Germany.

Received: 21 December 2015 Accepted: 12 April 2016

Published online: 18 April 2016

\section{References}

1. de Onis M, Blossner M, Borghi E. Global prevalence and trends of overweight and obesity among preschool children. Am J Clin Nutr. 2010; 92(5):1257-64

2. Jang $M$, Berry D. Overweight, obesity, and metabolic syndrome in adults and children in South Korea: a review of the literature. Clin Nurs Res. 2011; 20(3):276-91.

3. $\mathrm{Ng} \mathrm{M}$ et al. Global, regional, and national prevalence of overweight and obesity in children and adults during 1980-2013: a systematic analysis for the Global Burden of Disease Study 2013. Lancet. 2014;384(9945):766-81.

4. Grundy SM. Metabolic syndrome pandemic. Arterioscler Thromb Vasc Biol. 2008;28(4):629-36.

5. Cornier MA et al. The metabolic syndrome. Endocr Rev. 2008;29(7):777-822.

6. Friend $A, C$ raig $L$, Turner $S$. The prevalence of metabolic syndrome in children: a systematic review of the literature. Metab Syndr Relat Disord. 2013;11(2):71-80.

7. WHO. Global health risks mortality and burden of disease attributable to selected major risks. Geneva: World Health Organization; 2009.
8. WHO. Controlling the global obesity epidemic. WHO Available from: http:// www.who.int/nutrition/topics/obesity/en/. Accessed 26 Nov 2015.

9. WHO. WHO | Obesity. WHO; 2015. Available from: http://who.int/topics/ obesity/en/. Accessed 26 Nov 2015.

10. Jéquier E, Bray GA. Low-fat diets are preferred. Am J Med. 2002;113(9):41-6.

11. Willett $W$, Leibel R. Dietary fat is not a major determinant of body fat. Am J Med. 2002;113:47-59.

12. Hession M et al. Systematic review of randomized controlled trials of lowcarbohydrate vs. low-fat/low-calorie diets in the management of obesity and its comorbidities. Obes Rev. 2009;10(1):36-50.

13. Mozaffarian $D$ et al. Changes in diet and lifestyle and long-term weight gain in women and men. N Engl J Med. 2011;364(25):2392-404.

14. Brown PJ, Konner M. An anthropological perspective on obesity. Ann N Y Acad Sci. 1987;499(1):29-46.

15. Sumithran P, Proietto J. The defence of body weight: a physiological basis for weight regain after weight loss. Clin Sci (Lond). 2013;124(4):231-41.

16. Bes-Rastrollo $\mathrm{M}$ et al. Predictors of weight gain in a Mediterranean cohort: the Seguimiento Universidad de Navarra Study. Am J Clin Nutr. 2006;83(2):362-70.

17. French SA et al. Predictors of weight change over two years among a population of working adults: the Healthy Worker Project. Int J Obes Relat Metab Disord. 1994;18(3):145-54.

18. Rosell $M$ et al. Weight gain over 5 years in 21,966 meat-eating, fish-eating, vegetarian, and vegan men and women in EPIC-Oxford. Int J Obes. 2006; 30(9):1389-96

19. Schulz $M$ et al. Food groups as predictors for short-term weight changes in men and women of the EPIC-Potsdam cohort. J Nutr. 2002;132(6):1335-40.

20. Vergnaud $A$ et al. Meat consumption and prospective weight change in participants of the EPIC-PANACEA study. Am J Clin Nutr. 2010;92(2):398-407.

21. Henneberg M, Grantham J. Obesity - a natural consequence of human evolution. Anthropol Rev. 2014;77(1):1-10.

22. WHO. Global Health Observatory, the data repository. WHO; 2015. Available from: http://www.who.int/gho/database/en/. Accessed 26 Nov 2015.

23. FAO. FAOSTAT-Food Balance Sheet. 2015. Available from: http://faostat3.fao. org/. Accessed 26 Nov 2015.

24. D.A.T. Southgate, A.R.C.F.R.I., Norwich, UK. Joint FAOMHO/UNU Expert Consultation on Energy and Protein Requirements-The Rellationship between Food Composition and Available Energy. Rome: FAOMHO/UNU; 1981.

25. Davis $B$, Wansink $B$. Fifty years of fat: news coverage of trends that predate obesity prevalence. BMC Public Health. 2015;15:629:1-6.

26. den Engelsen $C$ et al. Development of metabolic syndrome components in adults with a healthy obese phenotype: a 3-year follow-up. Obesity (Silver Spring). 2013;21(5):1025-30.

27. Trøseid $M$ et al. Arterial stiffness is independently associated with interleukin-18 and components of the metabolic syndrome. Atherosclerosis. 2010;209(2):337-9.

28. FAO. Food balance sheets. A handbook. Rome: Food and Agriculture Organization; 2001.

29. Grantham JP et al. Modern diet and metabolic variance-a recipe for disaster? Nutr J. 2014:13:15:01-10.

30. The World Bank: International Comparison Program database: World Development Indicators. GDP (current US\$) per capita per year. 2010 Available from: http://data.worldbank.org. Accessed 26 Nov 2015.

31. Siervo $\mathrm{M}$ et al. Sugar consumption and global prevalence of obesity and hypertension: an ecological analysis. Public Health Nutr. 2014;17(3):587-96.

32. Roccisano D, Henneberg M. Soy consumption and obesity. Food Nutr Sci. 2012;03(02):260-6.

33. Basu $\mathrm{S}$ et al. The relationship of sugar to population-level diabetes prevalence: an econometric analysis of repeated cross-sectional data. PLoS One. 2013;8(2):e57873: 1-8.

34. Basu $S$ et al. Nutritional determinants of worldwide diabetes: an econometric study of food markets and diabetes prevalence in 173 countries. Public Health Nutr. 2013;16(1):1-8.

35. Weeratunga $P$ et al. Per capita sugar consumption and prevalence of diabetes mellitus - global and regional associations. BMC Public Health. 2014;14:186-91.

36. Giskes $\mathrm{K}$ et al. Socioeconomic position at different stages of the life course and its influence on body weight and weight gain in adulthood: a longitudinal study with 13-year follow-up. Obesity (Silver Spring). 2008;16(6):1377-81.

37. Nestle M. Increasing portion sizes in American diets: more calories, more obesity. J Am Diet Assoc. 2003;103(1):39-40.

38. Berentzen T, Sorensen TI. Physical inactivity, obesity and health. Scand J Med Sci Sports. 2007;17(4):301-2. 
39. The World Bank. Country and Lending Groups | Data. 2015. Available from: http://data.worldbank.org/about/country-and-lending-groups. Accessed 26 Nov 2015.

40. WHO. WHO regional offices. Available from: http://www.who.int. Accessed 26 Nov 2015.

41. The United Nations Educational Scientific and Cultural Organization. UNESCO Regions-Latin America and the Caribbean. 2014. Available from: http://www.unesco.org. Accessed 26 Nov 2015.

42. Asia-Pacific Economic Cooperation. Member Economies-Asia-Pacific Economic Cooperation. Available from: http://www.apec.org. Accessed 26 Nov 2015.

43. South Africa Development Community. Southern African Development Community: Member States. Available from: http://www.sadc.int. Accessed 06 Jun 2015.

44. Asia Cooperation Dialogue. Member Countries. Available from: http://www. acd-dialogue.org/. Accessed 26 Nov 2015.

45. Lin $Y$ et al. Plant and animal protein intake and its association with overweight and obesity among the Belgian population. Br J Nutr. 2011;105(7):1106-16.

46. Wang Y, Beydoun MA. Meat consumption is associated with obesity and central obesity among US adults. Int J Obes (Lond). 2009;33(6):621.

47. Bradlee $M$ et al. Food group intake and central obesity among children and adolescents in the Third National Health and Nutrition Examination Survey (NHANES III). Public Health Nutr. 2010;13(6):797-805.

48. Bujnowski $D$ et al. Longitudinal association between animal and vegetable protein intake and obesity among men in the United States: the Chicago Western Electric Study. J Am Diet Assoc. 2011;111(8):1150-5. e1.

49. Liu J et al. Predictive value for the Chinese population of the Framingham CHD risk assessment tool compared with the Chinese multi-provincial cohort study. JAMA-J Am Med Assoc. 2004;291(21):2591-9.

50. Wang $Z$ et al. Fatty and lean red meat consumption in China: differentia association with Chinese abdominal obesity. Nutr Metab Carbiovasc Dis. 2014:24(8):869-76.

51. Ryan YM. Meat avoidance and body weight concerns: nutritional implications for teenage girls. Proc Nutr Soc. 1997;56:519-24.

52. Li J et al. Incidence of obesity and its modifiable risk factors in Chinese adults aged 35-74 years. Zhonghua Liu Xing Bing Xue Za Zhi. 2014;35(4):349-53.

53. Pearce KL, Norman HC, Hopkins DL. The role of saltbush-based pasture systems for the production of high quality sheep and goat meat. Small Ruminant Research. 2010;91(1):29-38.

54. Lawrie RA, Ledward DA. Lawrie's meat science. 7th ed. Cambridge: Woodhead Publishing Limited; 2006.

55. Cordain $L$ et al. Plant-animal subsistence ratios and macronutrient energy estimations in worldwide hunter-gatherer diets. Am J Clin Nutr. 2000;71(3):682-92.

56. Roy RP. A Darwinian view of obstructed labor. American College Obstet Gynecol. 2003;101(2):397-401.

57. Eaton SB, Konner M, Shostak M. Stone-agers in the fast lane_ chronicdegenerative diseases in evolutionary perspective. Am J Med. 1988; 84(4):739-49.

58. Richards MP et al. FOCUS: Gough's Cave and Sun Hole Cave human stable isotope values indicate a high animal protein diet in the British Upper Palaeolithic. J Archaeol Sci. 2000;27(1):1-3.

59. Tarnopolsky MA et al. Evaluation of Protein-requirements for trained strength athletes. J Appl Phys. 1992;73(5):1986-95.

60. Foundation $\mathrm{H}$. Position statement on very low carbohydrate diets (April 2004). 2015.

61. Layman D et al. A moderate-protein diet produces sustained weight loss and long-term changes in body composition and blood lipids in obese adults. J Nutr. 2009;139(3):514-21.

62. Samaha F et al. A low-carbohydrate as compared with a low-fat diet in severe obesity. N Engl J Med. 2003;348(21):2074-81.

63. WHO. Diet, Nutrition and the Prevention of Chronic Diseases. Report of a Joint WHO/FAO Expert Consultation. In: Technical Report Series No. 916. Geneva: World Health Organization; 2003.

64. Elmadfa I. European nutrition and health report 2009. Basel; London: Karger; 2009

65. Vergnaud AC et al. Macronutrient composition of the diet and prospective weight change in participants of the EPIC-PANACEA study. PLoS One. 2013; 8(3):e57300.

66. Mikkelsen P, Toubro S, Astrup A. Effect of fat-reduced diets on 24-h energy expenditure: comparisons between animal protein, vegetable protein, and carbohydrate. Am J Clin Nutr. 2000;72(5):1135-41.
67. Toden $\mathrm{S}$ et al. High red meat diets induce greater numbers of colonic DNA double-strand breaks than white meat in rats: attenuation by high-amylose maize starch. Carcinogenesis. 2007;28(11):2355-62.

68. Sabate J, Wien M. Vegetarian diets and childhood obesity prevention. Am J Clin Nutr. 2010;91(5):1525S-9.

69. Tuso PJ et al. Nutritional update for physicians: plant-based diets. Perm J. 2013;17(2):61-6.

70. Key $T$ et al. Mortality in vegetarians and non-vegetarians: a collaborative analysis of 8300 deaths among 76,000 men and women in five prospective studies. Public Health Nutr. 1998;1(1):33-41.

71. Raubenheimer $D$ et al. Nutritional ecology of obesity: from humans to companion animals. Br J Nutr. 2015;113 Suppl:S26.

72. Wells JC. The evolution of human fatness and susceptibility to obesity: an ethological approach. Biol Rev Camb Philos Soc. 2006;81(2):183-205.

73. Belobrajdic D, Mclntosh G, Owens J. A high-whey-protein diet reduces body weight gain and alters insulin sensitivity relative to red meat in Wistar rats. J Nutr. 2004;134(6):1454-8.

74. Schwarz J, et al. Dietary Protein Affects Gene Expression and Prevents Lipid Accumulation in the Liver in Mice. PLoS ONE. 2012;7(10):e47303.

75. Ramel A, Jonsdottir MT, Thorsdottir I. Consumption of cod and weight loss in young overweight and obese adults on an energy reduced diet for 8 weeks. Nutr Metab Cardiovasc Dis. 2009;19(10):690-6.

76. Elliott $P$ et al. Association between protein intake and blood pressure: the INTERMAP Study. Arch Intern Med. 2006;166(1):79.

77. Westman EC. Is dietary carbohydrate essential for human nutrition? Am J Clin Nutr. 2002;75(5):951-3.

78. Sarwar $\mathrm{H}$. The importance of cereals (Poaceae: Gramineae) nutrition in human health: a review. J Cereals Oilseeds. 2013;4(3):32-5.

79. Latham MC. Human nutrition in the developing world. Rome: Food and Agriculture Organization of the United Nations; 1997.

80. Jensen H, N.B.N.J. The Squibb Institute for Medical Research. Our present knowledge of carbohydrate metabolism. Trans N Y Acad Sci. 2015;2:103-8.

81. Pi-sunyer FX. Effect of the composition of the diet on energy intake. Nutr Rev. 1990;48(2):94-105

82. Astrup A. Dietary composition, substrate balances and body fat in subjects with a predisposition to obesity. Int J Obes Relat Metab Disord. 1993;17 Suppl 3:S32-6. discussion S41-2.

83. Romieu I, et al. Energy intake and other determinants of relative weight. Am J Clin Nutr. 1988:47(3):406-12.

84. Drewnowski A et al. Sweet tooth reconsidered: taste responsiveness in human obesity. Physiol Behav. 1985;35(4):617-22.

85. Drewnowski A et al. Food preferences in human obesity- carbohydrates versus fats. Appetite. 1992;18(3):207-21.

86. Lissner L, Heitmann BL. Dietary fat and obesity: evidence from epidemiology. Eur J Clin Nutr. 1995;49:79-90.

87. Chen J et al. Diet, life-style, and mortality in China: a study of the characteristics of 65 Chinese counties. Oxford: Oxford University Press; 1990. Ithaca, N.Y: Cornell University Press.

88. Willett $W$. Is dietary fat a major determinant of body fat? Am J Clin Nutr. 1998;67(3):556S-62.

89. Centers for Disease Control and Prevention. Daily dietary fat and total foodenergy intakes - NHANES III, Phase 1, 1988-91. JAMA J Am Med Assoc. 1994:271(17):1309.

90. Kuczmarski RJ et al. Increasing prevalence of overweight among US adults. The National Health and Nutrition Examination Surveys, 1960 to 1991. JAMA. 1994;272(3):205

\section{Submit your next manuscript to BioMed Central and we will help you at every step:}

- We accept pre-submission inquiries

- Our selector tool helps you to find the most relevant journal

- We provide round the clock customer support

- Convenient online submission

- Thorough peer review

- Inclusion in PubMed and all major indexing services

- Maximum visibility for your research

Submit your manuscript at www.biomedcentral.com/submit 